\title{
Swertiamarin Contributes to Glucose Homeostasis via Inhibition of Carbohydrate Metabolizing Enzymes
}

\author{
Javed Ahamad, Naila Hassan, Saima Amin and Showkat R. Mir* \\ Faculty of Pharmacy, Hamdard University (Jamia Hamdard), Pharmacognosy and Phytochemistry, \\ New Delhi -110062, India
}

\begin{abstract}
Objective: Swertiamarin is a common secoiridoid found among the members of Gentianaceae. The present study aimed to establish the effectiveness of swertiamarin in achieving glucose homeostasis via inhibition of carbohydrate metabolizing enzymes by in-vitro and in-vivo studies. Materials and methods: Swertiamarin was obtained from dried whole plant samples of Enicostemma littorale Blume chromatographic fractionation over the silica gel column. Its effect on carbohydrate metabolizing enzymes viz., $\alpha$-amylase and $\alpha$-glucosidase were evaluated at 0.15 to $10 \mathrm{mg} / \mathrm{mL}$ in-vitro. The results were supplemented by anti-hyperglycemic studies in carbohydrate challenged mice pretreated with swertiamarin at a dose of $20 \mathrm{mg} / \mathrm{kg}$ body weight orally. Results: Swertiamarin was effective in inhibiting $\alpha$-amylase and $\alpha$-glucosidase with $\mathrm{IC}_{50}$ values of $1.29 \pm 0.25 \mathrm{mg} / \mathrm{mL}$ and $0.84 \pm 0.11 \mathrm{mg} / \mathrm{mL}$, respectively. The studies in starch and sucrose challenged mice showed that swertiamarin effectively restricted the increase in the peak blood glucose level (BGL). The increase in peak BGL was $49 \mathrm{mg} / \mathrm{dL}$ and $57 \mathrm{mg} / \mathrm{dL}$ only in the treatment groups compared to $70 \mathrm{mg} / \mathrm{dL}$ and $80 \mathrm{mg} / \mathrm{dL}$ in untreated groups after $30 \mathrm{~min}$ in starch and sucrose-fed mice, respectively. Acarbose $(10 \mathrm{mg} / \mathrm{kg}$ b.w.) also produced significant $(p<0.01)$ blood glucose lowering response in both the models. Conclusion: Swertiamarin was effective in the achieving stricter glycemic control in carbohydrate challenged mice through the inhibition of carbohydrate metabolizing enzymes.
\end{abstract}

Keywords: $\alpha$-Amylase, Enicostema littorale, $\alpha$-Glucosidase, Glucose Homeostasis, PPHG, Swertiamarin

\section{Introduction}

Diabetes mellitus is a metabolic syndrome caused by an absence or dysfunction of insulin. Worldwide, there is a dramatic increase in the number of people with diabetes in recent years. The higher blood glucose level is one of the main culprits in fermenting the complications inherent to diabetes such as neuropathy and nephropathy ${ }^{1}$. The glucose homeostasis is one of the pivotal therapeutic modality in the management diabetes. Normally it is maintained by a fine balancing act of insulin and glucagon in the body. Hydrolytic enzymes amylase and glucosidase are involved in the metabolism of polysaccharides to oligosaccharides and ultimately to glucose that is amenable to intestinal absorption. Inhibition of these enzymes lowers the amount of glucose entering the systemic circulation, while most of the carbohydrate from the diet leaves GIT undigested. Therefore, attaining glucose homeostasis through the inhibition of carbohydrate metabolizing

\footnotetext{
*Author for correspondence

Email:showkatrmir@gmail.com
} 
enzymes is an interesting strategy as it excludes the involvement of insulin (pancreas). It attains glucose metabolism and regulation beyond insulin and glucagon. Acarbose, voglibose and miglitol are the inhibitors of carbohydrate metabolizing enzymes used clinically to control postprandial hyperglycemia in diabetics ${ }^{2}$.

Swertiamarin (Figure 1) is the predominant secoiridoid glycoside reported from Enicostemma littorale Blume $\mathrm{B}^{3}$. E. littorale, locally known as Chotachiretta in India, is included in several traditional antidiabetic medicines. It is a glabrous perennial herb found widely in India. E. littorale is a traditional bitter, stomachic and febrifuge ${ }^{4}$. It is also reported to have anti-inflammatory ${ }^{5}$, anticancer ${ }^{6}$, hypoglycemic ${ }^{7}$ and hypolipidemic ${ }^{8}$ activities. There are no previous studies of evaluation of the role of swertiamarin in glucose homeostasis. Hence, the present study aimed to establish the effectiveness of swertiamarin in achieving glucose homeostasis via inhibition of carbohydrate metabolizing enzymes by in-vitro and in-vivo studies.

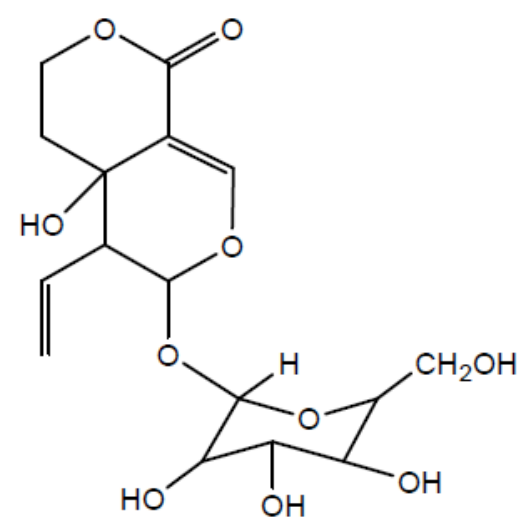

Fig. 1. Chemical structure of swertiamarin.

\section{Materials and Methods}

\subsection{Plant Material and Chemicals}

The samples of E. littorale (dried whole herb) collected from Tehri, Garhwal, Uttarakhand, India was procured through Universal Biotic, Delhi. It was authenticated by Taxonomist, Jamia Hamdard University, Delhi, India. A voucher specimen of the sample (PRL/2011-12/1856/01) was deposited in the Phytopharmaceutical Research Lab., Hamdard University, New Delhi. Enzymes a-amylase and $\alpha$-glucosidase were purchased from SRL, Bangalore,
India. PNPG ( $p$-nitrophenyl- $\alpha$-D-glucopyranoside and DNS (3,5-dinitrosalicylic acid) were purchased from Merck India, Mumbai, India. Acarbose was generously gifted by Medley Pharmaceutical Ltd., J\&K, India. All other solvents and chemicals were of analytical grade and purchased from S.D. Fine, Mumbai, India.

\subsection{Instruments}

Melting point was recorded on Perfit apparatus, India. UV spectrum was scanned on the UV-visible spectrometer, Shimadzu, Japan; IR spectra were recorded in $\mathrm{KBr}$ on Biorad spectrometer 135 instruments, USA; NMR data in $\mathrm{CDCl}_{3}$ were recorded on Bruker Spectrosp in 400 $\mathrm{MHz}$, Switzerland. Mass spectra were scanned in positive mode on Waters Q-TOF Synapt mass spectrometer, UK.

\subsection{Isolation of Swertiamarin}

Dried sample was powdered using a grinder. About $1 \mathrm{~kg}$ of powder was exhaustively extracted with methanol (5 $\mathrm{L}$ ) in a Soxhlet apparatus for $72 \mathrm{~h}$. The extract was filtered and dried in vacou at $50^{\circ} \mathrm{C}$ in a rotary vacuum evaporator. The methanolic residue $(28.5 \% \mathrm{w} / \mathrm{w})$ was suspended in water $(1 \mathrm{~L})$ and then successively partitioned with hexane, ethyl acetate and $n$-butanol thrice ( $1 \mathrm{~L}$, each). The $n$-butanol fraction $(4.8 \% \mathrm{w} / \mathrm{w})$ was subjected to normal phase flash column chromatography using silica gel (200400 mesh). The column was packed in $n$-butanol and eluted with $n$-butanol-methanol (90:10, 80:20 and 70:30 $\mathrm{v} / \mathrm{v}$ ) and different fractions of $250 \mathrm{~mL}$ each was collected. The fractions were subjected to TLC to check their homogeneity. Chromatographically identical fractions were combined and concentrated. Fractions (1-9) from $n$-butanol-methanol (90:10 v/v) eluants were pooled and yielded needle-shaped crystals in methanol on keeping. NMR, mass, and other spectroscopic data were recorded for characterization of isolated compounds ${ }^{9}$.

\subsection{In-vitro Enzyme Inhibition Assays}

The enzyme inhibition assays were carried out for swertiamarin doses from 0.15 to $10 \mathrm{mg} / \mathrm{mL}$ as per the established protocol detailed elsewhere. Briefly, a-amylase inhibitory activity was determined by incubating swertiamarin or acarbose in sodium phosphate buffer ( $\mathrm{pH}$ 6.9) with $\alpha$-amylase solution (1 U/ $\mathrm{mL}$ in phosphate buffer) at $25^{\circ} \mathrm{C}$ for $30 \mathrm{~min}$ in test tubes. 
Next starch solution in phosphate buffer $(0.25 \%)$ in a ratio of 1:10 was added as a substrate to each tube. The reaction was started by incubation at $37^{\circ} \mathrm{C}$ for $5 \mathrm{~min}$. DNS reagent was added to the reaction mixture and heated for $10 \mathrm{~min}$ on a water bath and allowed to cool to room temperature. The absorbance at $540 \mathrm{~nm}$ was recorded after making up the volume to $10 \mathrm{~mL}$ with distilled water. Control readings were recorded likewise only replacing test sample with buffer ${ }^{10}$. For $\alpha$-glucosidase inhibitory activity, swertiamarin or acarbose in phosphate buffer ( $\mathrm{pH}$ 6.8) was incubated with $\alpha$-glucosidase solution at $37^{\circ} \mathrm{C}$ for 20 min in a 94-well plate. Later PNPG solution in phosphate buffer as substrate was added to each well before incubation for $20 \mathrm{~min}$ at $37^{\circ} \mathrm{C}$. Sodium carbonate is added to each well to terminate the reaction. Record absorbance at $405 \mathrm{~nm}$ using a microplate reader and compared to a control where buffer solution replaces the test sample ${ }^{11}$.

The percent inhibition of enzymes was calculated as follows:

$$
\% \text { Inhibition }=\frac{A \text { control }-A \text { test }}{A \text { control }} \times 100
$$

The concentration required for inhibiting enzyme activity by $50 \%$ under the assay conditions was referred as $\mathrm{IC}_{50}$ value.

\subsection{In-vivo Studies}

\subsubsection{Animals}

Wistar albino mice (30-40 g) were kept in clean polypropylene cages and were fed with pellets of standard diet (Lipton rat feed, Ltd., Pune) and water ad libitum. The animals were accustomed to with dark/ light cycle $(12 / 12 \mathrm{~h})$. and room temperature $25 \pm 2{ }^{\circ} \mathrm{C}$ for one week before the start of the experiment. The study protocol was duly approved by the Institutional Animal Ethical Committee, Hamdard University, New Delhi, India (Reg. no. JH/CAHF/173/CPCSEA/28 ${ }^{\text {th }}$ Jan, 2000 with approval no. 2012/926).

\subsubsection{Oral Carbohydrate Challenge Tests}

Mice have fasted overnight for $12 \mathrm{~h}$ but had free access to water. The animals were randomly divided into seven groups of six mice each. Group I served as normal control which received $1 \mathrm{~mL} / \mathrm{kg}$ b.w. vehicle (0.5\% CMC in distilled water). For the oral starch tolerance test, group II served as starch challenge control that received starch (3 g/kg b.w.); group III received acarbose as a standard drug (10 mg/kg b.w., p.o.) while as group IV was administered swertiamarin ( $20 \mathrm{mg} / \mathrm{kg}$ b.w., p.o.). Groups III and IV were fed starch after $20 \mathrm{~min}$ of the treatments. For oral sucrose tolerance test group V served as sucrose challenged control that received sucrose $(4 \mathrm{~g} / \mathrm{kg}$ b.w.). Groups VI and VII received acarbose $(10 \mathrm{mg} / \mathrm{kg}$ b.w., p.o.) and swertiamarin $(20 \mathrm{mg} / \mathrm{kg}$ b.w., p.o.), respectively followed by sucrose after $20 \mathrm{~min}$ of the treatments. Blood was taken from the tail vein at $0,30,60,90$ and 120 min after the carbohydrate challenge. Blood glucose level (BGL) was measured using one-touch glucometer (myLifePura, Switzerland). The AUC was calculated using Trapezoidal method ${ }^{12}$.

\subsection{Statistical Analysis}

Data were statistical evaluated using ANOVA followed by Dunnett's $t$-test. Values were expressed as mean $\pm S D$ and $p<0.05$, were considered significant.

\section{Results}

\subsection{Isolation of Swertiamarin}

Swertiamarin was obtained from $n$-butanol fraction of the E. littorale extract by normal column chromatography over silica gel with $n$-butanol-methanol $(90: 10 \mathrm{v} / \mathrm{v})$ elution. Fractions 1-3 yielded slightly brownish mass that on repeated recrystallization from methanol produced colourless needle-shaped crystals of swertiamarin (750 mg; $0.075 \%$ yield), mp $110-111^{\circ} \mathrm{C}$ (reported value, 113 $114^{\circ} \mathrm{C}$ ). Its UV absorption peaks in $\mathrm{MeOH}$ at 224 and 291 $\mathrm{nm}$ were characteristic of $\alpha, \beta$-unsaturated lactone, the presence of which was also supported by a typical band at $1585 \mathrm{~cm}^{-1}$ in its FTIR spectrum. Its +ve-EIMS exhibited a pseudo-molecular ion peak at $\mathrm{m} / z 375[\mathrm{M}+1]^{+}$, consistent with molecular formula $\mathrm{C} 16 \mathrm{H} 22 \mathrm{O} 10$. The structure of swertiamarin was confirmed by comparing ${ }^{1} \mathrm{H}$ and ${ }^{13} \mathrm{C}$ NMR with the previously reported data ${ }^{13}$.

\subsection{Enzyme Inhibition by Swertiamarin}

The percentage inhibition of $\alpha$-amylase by swertiamarin and acarbose is depicted in Figure 2. Swertiamarin 
exhibited a concentration dependent inhibition of $\alpha$-amylase that varied from $64.07 \pm 4.64$ to $12.54 \pm 2.69 \%$ for 10 to $0.15 \mathrm{mg} / \mathrm{mL}$, respectively. Acarbose also showed a concentration dependent response that varied from $82.84 \pm 3.34$ to $31.29 \pm 4.35 \%$ for 10 to $0.15 \mathrm{mg} /$ $\mathrm{mL}$, respectively. The $\mathrm{IC}_{50}$ values for swertiamarin and acarbose were found to be $1.25 \pm 0.29$ and $0.42 \pm 0.02 \mathrm{mg} /$ $\mathrm{mL}$, respectively. The results of $\alpha$-glucosidase inhibitory study are shown in Figure 3. Swertiamarin showed concentration dependent inhibition of a-glucosidase varying from $73.09 \pm 1.21$ to $11.47 \pm 3.51 \%$ for 10 to $0.15 \mathrm{mg} / \mathrm{mL}$, respectively. Acarbose also showed a concentration dependent response that varied from $83.05 \pm 3.27$ to $16.81 \pm 2.68 \%$ for 10 to $0.15 \mathrm{mg} / \mathrm{mL}$, respectively. The $\mathrm{IC}_{50}$ values for swertiamarin and acarbose were found as $0.85 \pm 0.18$ and $1.41 \pm 0.07 \mathrm{mg} /$ $\mathrm{mL}$, respectively.

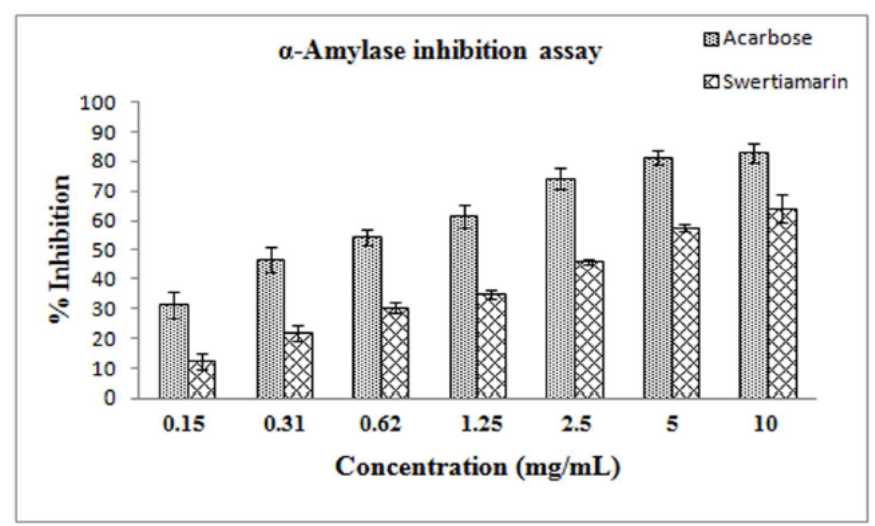

Fig. 2. Percentage inhibition of a-amylase by swertiamarin compared to acarbose.

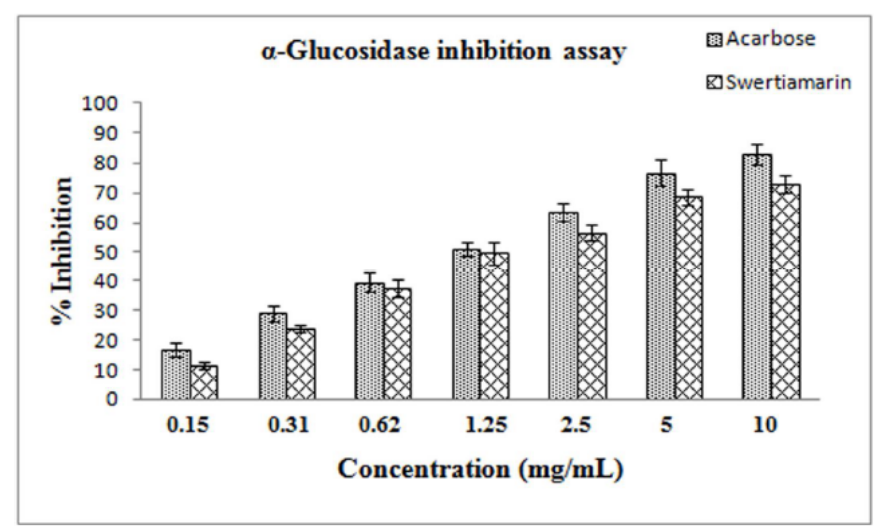

Fig.3. Percentage inhibition of a-glucosidase by swertiamarin compared to acarbose.

\subsection{Antihyperglycemic Activity}

In-vivo studies revealed that oral administration of starch ( $3 \mathrm{~g} / \mathrm{kg}$ b.w.) and sucrose $(4 \mathrm{~g} / \mathrm{kg}$ b.w.) produced significantly $(p<0.01)$ increase in blood glucose level (BGL) in mice resulting in hyperglycemia due to carbohydrate overdose. Table 1 depicts the effect of oral carbohydrate challenge in mice pre-treated with swertiamarin (Group IV and VII). It blunted the effect of carbohydrate overload as signified by about $49 \mathrm{mg} /$ $\mathrm{dL}$ and $57 \mathrm{mg} / \mathrm{dL}$ increase in peak BGL in the treatment groups compared to $70 \mathrm{mg} / \mathrm{dL}$ and $80 \mathrm{mg} / \mathrm{dL}$ increase in peak BGL in untreated groups after $30 \mathrm{~min}$ in starch and sucrose-fed mice, respectively. Acarbose (Group III and VI) also produced significantly $(p<0.01)$ blood glucose lowering response in both the models. Figure 4 represents a comparison of the effects of swertiamarin and acarbose with respect to area under curve (AUC) in carbohydrate-induced hyperglycemia. Swertiamarin produced a reduction of about $15 \%$ and $14 \%$ in AUC of starch and sucrose-fed mice compared to respective controls. The reduction by swertiamarin in AUC was comparable to that of acarbose.

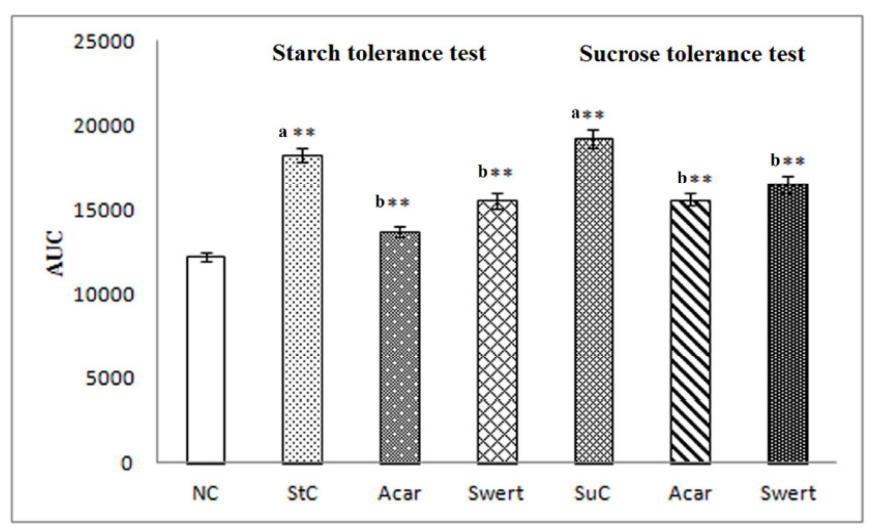

Fig. 4. Comparison of the effects of swertiamarin and acarbose with respect to area under curve (AUC) in carbohydrate-induced hyperglycemia.

\section{Discussion}

Swertiamarin has been reported as antihyperlipidaemic $^{14,15}$ hypoglycemic ${ }^{16,17}$ and antinociceptive $^{18}$ but its role in achieving glycemic control have not been investigated. The inhibitors of 
Table 1: Effect of swertiamarin on blood glucose level in carbohydrate challenged mice

\begin{tabular}{|c|c|c|c|c|c|}
\hline \multirow[t]{3}{*}{ Group } & \multicolumn{5}{|c|}{ Blood glucose level (mg/dL) } \\
\hline & $0 \mathrm{~min}$ & $30 \mathrm{~min}$ & $60 \mathrm{~min}$ & $90 \mathrm{~min}$ & $120 \mathrm{~min}$ \\
\hline & \multicolumn{5}{|c|}{ Starch tolerance test } \\
\hline NC & $101.4 \pm 1.20$ & $100.8 \pm 1.07$ & $102 \pm 1.14$ & $103 \pm 0.45$ & $102 \pm 1.09$ \\
\hline StC & $100.6 \pm 1.54$ & $170.4 \pm 1.86^{a^{* * *}}$ & $161.8 \pm 1.93^{\mathrm{a}^{* * *}}$ & $154.6 \pm 1.07^{\mathrm{a}, * *}$ & $146 \pm 1.64^{\mathrm{a}, * *}$ \\
\hline Acar & $98.4 \pm 0.24$ & $130.8 \pm 2.27^{b_{, * *}^{* *}}$ & $115.4 \pm 1.33^{\mathrm{b}, * *}$ & $109.8 \pm 0.73^{b_{, * *}^{* *}}$ & $106.4 \pm 0.75^{b_{, * *}^{* *}}$ \\
\hline Swert & $98 \pm 0.55$ & $149.6 \pm 2.69^{b_{,}^{*}}$ & $132.4 \pm 2.38^{\mathrm{b}, * *}$ & $127.6 \pm 1.44^{\mathrm{b}, * *}$ & $119.6 \pm 1.03^{b_{, * *}^{* *}}$ \\
\hline \multicolumn{6}{|c|}{ Sucrose tolerance test } \\
\hline SuC & $102.8 \pm 0.97$ & $180.6 \pm 2.25^{a_{a^{* *}}}$ & $175.2 \pm 2.08^{\mathrm{a}^{* * *}}$ & $160.6 \pm 2.76^{\mathrm{a}_{1}^{* *}}$ & $148.8 \pm 1.07^{a, * *}$ \\
\hline Acar & $102.2 \pm 1.2$ & $143.8 \pm 1.66^{b_{, * *}^{* *}}$ & $139.8 \pm 1.16^{\mathrm{b}, * *}$ & $128.8 \pm 1.56^{\mathrm{b}, * *}$ & $115.6 \pm 0.68^{b_{, * *}^{* *}}$ \\
\hline Swert & $101.6 \pm 0.53$ & $157.2 \pm 0.74^{\mathrm{b}, *}$ & $149.4 \pm 0.52^{\mathrm{b}, *}$ & $133.4 \pm 0.69^{b_{,}^{* *}}$ & $123.6 \pm 0.30^{\mathrm{b}, * *}$ \\
\hline
\end{tabular}

Data are expressed as mean $\pm \mathrm{SD}, \mathrm{N}=6 . \mathrm{NC}$ : normal control ( $1 \mathrm{~mL} / \mathrm{kg}$ b.w. of $0.5 \% \mathrm{CMC}$ in distilled water); StC: starch control (3 $\mathrm{g} / \mathrm{kg}$ b.w.); SuC: sucrose control (4 g/kg b.w.); Acar: acarbose (10 mg/kg b.w.) and Swert: swertiamarin ( $20 \mathrm{mg} / \mathrm{kg}$ b.w.). ${ }^{\mathrm{a} C a r b o h y-}$ drate challenged control vs. normal control, ${ }^{* *} \mathrm{p}<0.01$. ${ }^{\mathrm{b}}$ Treated group vs. carbohydrate challenged control, ${ }^{*} \mathrm{p}<0.05,{ }^{* *} \mathrm{p}<0.01$.

carbohydrate metabolizing enzymes such as acarbose significantly affect the activities of both these enzymes. The non-specificity of action of these inhibitors results in flatulence that is due to an excessive inhibition of $\alpha$-amylase leading to abnormal bacterial fermentation of undigested carbohydrates ${ }^{19}$. Therefore, agents with comparatively more inhibitory activity against $\alpha$-glucosidase than against $\alpha$-amylase will be helpful to overcome this challenge. Our results indicate that swertiamarin showed stronger inhibition against a-glucosidase $\left(\mathrm{IC}_{50} 0.84 \pm 0.11 \mathrm{mg} / \mathrm{mL}\right)$ than $\alpha$-amylase $\left(\mathrm{IC}_{50} 1.29 \pm 0.25 \mathrm{mg} / \mathrm{mL}\right)$. The inhibition for $\alpha$-glucosidase by swertiamarin was more than that of acarbose ( $\mathrm{IC}_{50}$ $1.45 \pm 0.09 \mathrm{mg} / \mathrm{mL}$ ). In in-vivo experiments, pretreatment with swertiamarin restricted the blood glucose excursions and decreased both peak BGL and AUC in starch and sucrose challenged mice and the effect was comparable to acarbose. Swertiamarin seemed to inhibit the carbohydrate metabolizing enzymes in the brush border of the small intestine. It successfully delayed the carbohydrate absorption. The retardation and delay of carbohydrate metabolism and absorption by swertiamarin offers a prospective therapeutic approach for the management of PPHG for pre-diabetics or who have blood glucose levels only slightly above the level considered serious for management through oral hypoglycemics or insulin.

\section{Conclusion}

The present study demonstrated the role of swertiamarin in inhibiting $\alpha$-amylase and $\alpha$-glucosidase enzymes. Swertiamarin was effective in the achieving stricter glycemic control in carbohydrate challenged mice through the inhibition of carbohydrate metabolizing enzymes. A rapid method for its preparative isolation from E. littorale using column chromatography was also developed.

\section{Acknowledgements}

This research work was funded by University Grants Commission, New Delhi, India, under Grant No. MRP42-704/2013, SR.

\section{Declaration of Interest}

The authors declare no conflict of interest.

\section{Disclosure}

Part of this article was previously published in Planta Medica. 2014; 80:13. 


\section{References}

1. Gin H, Rigalleau V. Post-prandial hyperglycemia and diabetes. Diabetes and Metabolism. 2000; 26:265-72.

2. Subramanian R, Asmawi MZ, Sadikun A. In-vitro $\alpha$-glucosidase and $a$-amylase enzyme inhibitory effects of Andrographis paniculata extract and andrographolide. Acta Biochimica Polonica. 2008; 55(2):391-8.

3. Jensen SR, Schripsema J. Chemotaxonomy and pharmacology of Gentianaceae. Gentianaceae systematics and natural history. Cambridge University Press; 2002. p. 573-631.

4. Nadkarni KM. Indian Materia Medica. Mumbai: Popular Prakashan Pvt. Ltd.; 2007; vol. 1:185.

5. Sadique J, Chandra T, Thenmozhi V, Elango V. The antiinflammatory effects of Enicostemma littorale and Mollugo cerviana. Biochemical Medicine and Metabolic Biology. 1987; 37:167-76.

6. Kavimani S, Manisenthlkumar KT. Effects of methanolic extract of Enicostemma littorale on Dalton's ascetic lymphoma. Journal of Ethnopharmacology. 2000; 71:34952.

7. Maroo J, Vasu VT, Aalinkeel R, Gupta S. Glucose lowering effect of aqueous extract of Enicostemma littorale Blume in diabetes: a possible mechanism of action. Journal of Ethnopharmacology. 2002; 81:317-20.

8. Sonawane RD, Vishwakarma SL, Lakshmi S, Rajani M, Padh H, Goyal RK. Amelioration of STZ-induced type 1 diabetic nephropathy by aqueous extract of Enicostemma littorale Blume and swertiamarin in rats. Molecular and Cell Biochemistry. 2010; 340:1-6.

9. Ahamad J, Amin S, Ahmad J, Mir SR. Response surface methodology for optimization of ultrasound assisted extraction of swertiamarin from Enicostema littorale Blume. Current Bioactive Compounds. 2016; 12(2):87-92.

10. Hassan N, Ahamad J, Amin S, Mujeeb M, Mir SR. Rapid preparative isolation of erythrocentaurin from
Enicostemma littorale by medium-pressure liquid chromatography, its estimation by high-pressure thinlayer chromatography, and its $\alpha$-amylase inhibitory activity. Journal of Separation Science. 2015; 38(4):592-8.

11. Dong HQ, Li M, Zhu F, Liu FL, Huang JB. Inhibitory potential of trilobatin from Lithocarpus polystachyus Rehd against $\alpha$-glucosidase and $\alpha$-amylase linked to type 2 diabetes. Food Chemistry. 2012; 130:261-6.

12. Purves RD. Optimum numerical integration methods for estimation of area-under-the-curve (AUC) and area underthe moment-curve (AUMC). Journal of Pharmacokinetics and Biopharmaceutics.1992; 20:211-27.

13. Anwar M, Ahmad M, Aslam M, Aftab K. Enicostema littorale: a new source of swertiamarin. Pakistani Journal of Pharmaceutical Sciences. 1996; 9(1):29-35.

14. Vaidya H, Rajani M, Sudarsanam V, Padh H, Goyal R. Antihyperlipidaemic activity of swertiamarin, asecoiridoid glycoside in poloxamer-407-induced hyperlipidaemic rats. Journal of Natural Medicine. 2009; 63:437-42.

15. Vaidya H, Rajani M, Sudarsanam V, Padh H, Goyal R. Swertiamarin: a lead from Enicostemma littorale Blume for anti-hyperlipidaemic effect. European Journal of Pharmacology. 2009; 617(1-3):108-12.

16. Vaidya H, Goyal RK, Cheema SK. Anti-diabetic activity of swertiamarin is due to an active metabolite, gentianine, that up regulates PPAR-g gene expression in 3T3-L1 cells. Phytotherapy Research. 2012; 27(4):624-7.

17. Patel MB, Mishra SH. Hypoglycemic activity of C-glycosyl flavonoid from Enicostemma hyssopifolium. Pharmaceutical Biology. 2011; 49(4):383-91.

18. Jaishree V, Badami S, Kumar RM, Tamizhmani T. Antinociceptive activity of swertiamarin isolated from Enicostemma littorale. Phytomedicine. 2009; 16:227-32.

19. Ahamad J, Naquvi KJ, Mir SR, Ali M, Shuaib M. Review on role of natural alpha-glucosidase inhibitors for management of diabetes mellitus. International Journal of Biomedical Research. 2011; 6:374-80. 